\title{
Net-zero emission residential building in temperate weather condition
}

\author{
Mohammad T. Arif* and Amanullah M. Than Oo \\ School of Engineering, Faculty of Science, Engineering and Built Environment, Deakin University, Geelong Waurn Ponds \\ Campus, Geelong, VIC 3220, Australia
}

Received: 24 January 2017 / Received in final form: 3 July 2017 / Accepted: 27 July 2017

\begin{abstract}
Residential load consumes a significant amount of grid energy for electrical and heating or cooling application. Greenhouse gas (GHG) emission or equivalent $\mathrm{CO}_{2}$ emission is the direct or indirect effect from either form of these energy uses. Energy demand is increasing with the addition of various new home appliances and energy price is also going up. Various initiatives can be taken to reduce energy demand. However the best way is by improving energy efficiency and that eventually reduces the emission. Using renewable energy (RE) to support local load demand is another approach to reduce $\mathrm{CO}_{2}$ emission. However effective use of RE depends on the climatic condition and synchronization of load-demand and local generation. Although unmatched energy from local RE generation can be sold back to the grid, the same amount of energy has to be purchased from the grid at higher cost. When the overall total amount of GHG emission in a year can be balanced by improving energy efficiency and by increasing local RE generation the condition of the house can be termed as zero emission house. This paper investigates the possibility of net-zero emission house in temperate weather condition in Geelong, Australia considering the cost of all relevant components. It was found that net-zero emission building can be implemented and can effectively reduce a total of $44 \mathrm{Mt}$ of $\mathrm{CO}_{2}$ emission in a year from all 9 million residential buildings in Australia.
\end{abstract}

\section{Introduction}

A net-zero emission building refers to a building where yearly average emission becomes zero. Emission from the building depends on how much energy is consumed and what are the sources of energy of the building. Australia's energy consumption is primarily composed of $94 \%$ from fossil fuel and $6 \%$ from renewable energy (RE) sources [1]. Australia is world's 12th largest energy consumer in 2013 and ranked 17th on per person basis [1]. Australia is responsible for around $1.3 \%$ of global carbon emission [2], therefore pressure is rising locally and globally to reduce carbon emission. Australia has a target to reduce Greenhouse gas (GHG) emission $5 \%$ below 2000 level by 2020 and 26-28\% below 2005 level by 2030 [2]. Residential, commercial, mining and services are the second largest energy-consuming sectors [3,4]. Australia has over 9 million homes and projected to 12.7 million in 2036 [5] therefore a significant contribution of GHG emission will continue from these residential buildings if not controlled.

This paper concentrates on the emission reduction from residential buildings. The aim of this paper is to investigate the possibility to achieve a net-zero emission residential

\footnotetext{
* e-mail: m.arif@deakin.edu.au
}

building in Geelong, Australia. The weather in Geelong is temperate type according to RP-884 thermal comfort database [6]. In temperate weather region temperature fluctuation is very high in short time therefore overall energy demand is higher around the year. Eventually this energy consumption is directly or indirectly related to GHG emission. In this paper the load demand of a threebedroom house in Geelong was considered, cost of energy $(\mathrm{COE})$ and grid emission rate was considered to minimize the energy demand and examined how to meet the energy demand from onsite RE such as roof-top solar photovoltaic (PV) to offset the net yearly GHG emission. Comparing various configurations with updated cost and emission data from various sources, an optimised system configuration was identified that makes the three-bedroom house in Geelong as the net-zero emission building.

\section{Background}

The common form of energy application in a house is for space conditioning, water heating, electrical appliances and for lighting. The common source of the energy for a house is grid connected electricity and/or gas. One of the effects of energy conversion is carbon emission which can be from direct application like combustion in boilers or furnaces 


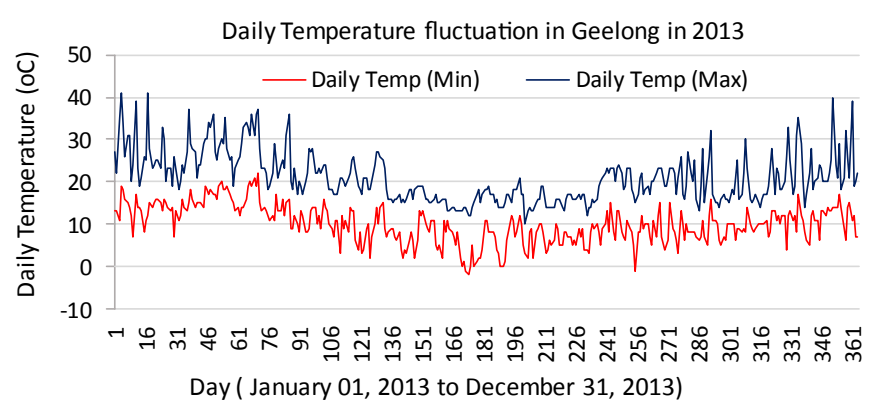

Fig. 1. Daily temperature fluctuation in Geelong in 2013.

onsite or from indirect application associated with consumption like purchasing electricity, heating and cooling. Fossil fuels like coal, natural gas, petroleum oil are mostly explored and utilized source of energy for electricity generation and for most other domestic and commercial applications. As a consequence, GHG or equivalent carbon emission into the atmosphere is increasing [7]. Worldwide energy use in buildings (including houses) accounted for over $40 \%$ of primary energy use and that contributes to $24 \%$ of GHG emission [8].

Indoor comfort temperature depends on the outdoor air temperature and energy requirement can be reduced by designing natural and hybrid ventilation in many moderate climate zones of the world [6]. Modern building codes, practices and governments initiatives have improved the insulation on new houses in Australia which eventually improves the in-house heating/cooling condition. However, a lot of energy is consumed by electrical appliances. A typical Australian house uses around $6.5 \mathrm{MWh} /$ year of electricity [9]. Therefore load pattern, information of weather that influence the load and emission from the house are essential to know to estimate the ways to reduce the carbon emission to zero.

\subsection{Weather condition}

This paper considered a residential building in Geelong, Australia where weather condition is temperate and temperature fluctuation is very high. Figure 1 shows the daily temperature change in 2013 , which indicates the higher demand of energy for the whole year. Geelong has four climatic seasons as summer (December-February), autumn (March-May), winter (June-August) and spring (September-November). From weather data [10] in Geelong it is found that in 2013 minimum temperature was $-2^{\circ} \mathrm{C}$ and maximum $41^{\circ} \mathrm{C}$. Maximum temperature fluctuation observed in 1 day in 2013 was $29^{\circ} \mathrm{C}$ in summer, $20^{\circ} \mathrm{C}$ in autumn, $16^{\circ} \mathrm{C}$ in winter and $22^{\circ} \mathrm{C}$ in spring as presented in Figure 1. Therefore houses in this area require both heating and cooling and consume a significant amount of energy.

\subsection{Residential load}

Load demand varies with different conditions (number of people, number of appliances and how the appliances are used and householders individual behaviour, etc.), however a trend of residential load demand profile was developed in
2014 by surveying 4000 households in Australia [11]. The total load demand includes electrical and thermal load. Thermal load can be supported by other source, like using natural gas or can be used with equivalent electricity supply.

Average residential electricity usage in weekdays in Victoria is $13.51 \mathrm{kWh} / \mathrm{d}$ in summer, $14.57 \mathrm{kWh} / \mathrm{d}$ in autumn, $17.70 \mathrm{kWh} / \mathrm{d}$ in winter and $14.24 \mathrm{kWh} / \mathrm{d}$ in spring during the period of 2009-10[12]. However in Geelong a three-bedroom house has daily electricity demand of $10.3 \mathrm{kWh} / \mathrm{d}$ in summer, $11.2 \mathrm{kWh} / \mathrm{d}$ in autumn, $13.5 \mathrm{kWh} / \mathrm{d}$ in winter and $9.6 \mathrm{kWh} / \mathrm{d}$ in spring [11] and if thermal load demand is supported by equivalent electrical source the daily electricity demand becomes $15.9 \mathrm{kWh} / \mathrm{d}$ in summer, $18.1 \mathrm{kWh} / \mathrm{d}$ in autumn, $26.1 \mathrm{kWh} / \mathrm{d}$ in winter and $16.4 \mathrm{kWh} / \mathrm{d}$ in spring [11]. Figure 2 illustrates daily load profile of a three-bedroom house in Geelong. Loads are distributed in four seasonal profiles and in Figure 2, blue coloured profile shows only electrical load and red coloured profile shows both electrical and thermal equivalent electrical load to present the total residential load demand.

\subsection{Carbon emission}

Emission comes from various energy conversion processes and emission from electricity generation is either from on-site generator directly or from grid energy contribution to the load indirectly and the following pollutants emit in different rates. Total emission is measured as yearly emission of emitted gases in $\mathrm{kg} /$ year and emission per capita or emission factor in $\mathrm{g} / \mathrm{kWh}$. When energy is purchased from grid, the grid-related emission is determined by the emission factor and total energy purchase from grid. The emission factors of different pollutant gases are $\mathrm{CO}_{2}$ (carbon-dioxide) $632.0 \mathrm{~g} /$ $\mathrm{kWh}, \mathrm{CO}$ (carbon-monoxide) $0.7 \mathrm{~g} / \mathrm{kWh}, \mathrm{UHC}$ (unburned hydrocarbons) $0.08 \mathrm{~g} / \mathrm{kWh}, \quad \mathrm{PM}$ (particulate matter) $0.052 \mathrm{~g} / \mathrm{kWh}, \mathrm{SO}_{2}$ (sulphur-dioxide) $2.74 \mathrm{~g} / \mathrm{kWh}$ and $\mathrm{NO}_{X}$ (nitrogen oxides) $1.34 \mathrm{~g} / \mathrm{kWh}[13]$.

\section{Emission reduction from residential building}

As emission is directly related to the amount of energy used therefore reduction of emission is also related to the reduction of energy use. Net home energy use can be reduced by (a) improving energy efficiency and (b) by incorporating on-site RE sources [14]. Many countries around the world including Australia is involved in joint research to develop Net-Zero Energy Solar Building (NetZEB) [8] to reduce building energy consumption and GHG emission.

\subsection{Building energy efficiency}

One of the key factors to reduce carbon emission is to improve building energy efficiency. When constructing a house, its site and surroundings have to be taken into account to control the house's thermal condition and the amount of lighting. Energy efficiency at home can be improved by (a) minimizing energy use (b) improving home energy rating and (c) by improving appliances energy 


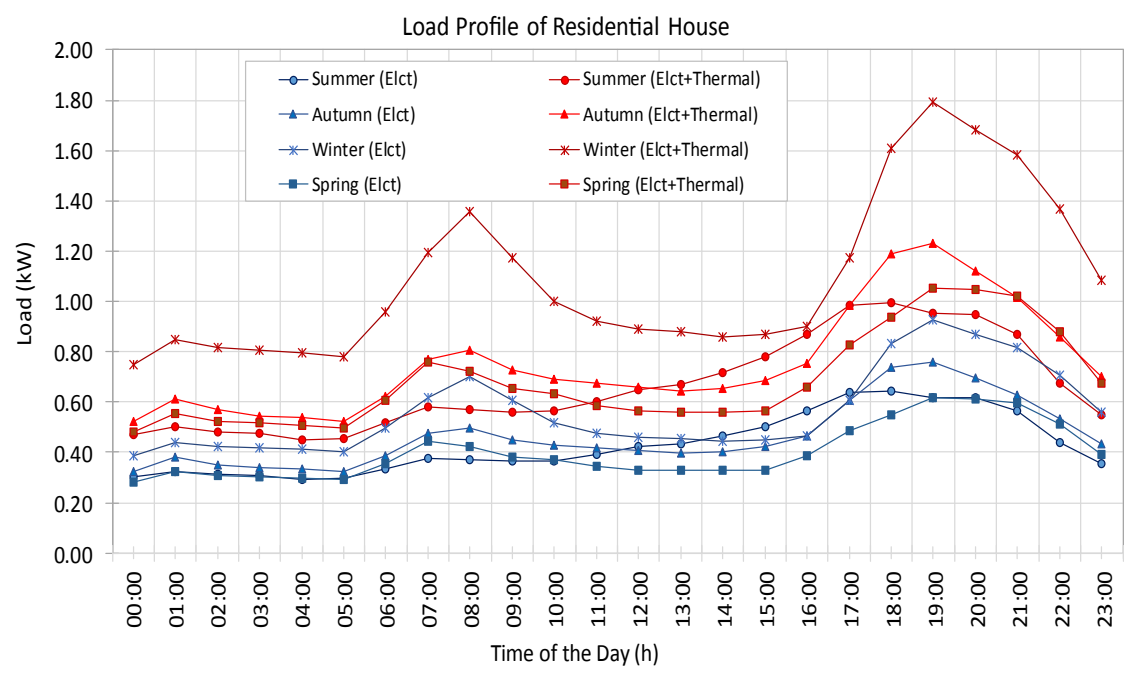

Fig. 2. Residential Building Load profile with seasonal variation.

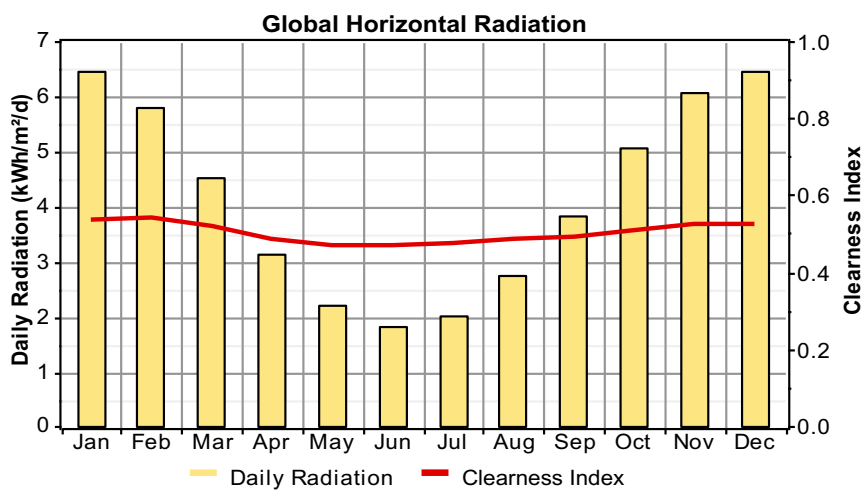

Fig. 3. Daily average solar radiation in Geelong area.

rating. Resident's behaviour in maintaining thermal condition and choice of appliances impacts on energy consumption. In Australia, Nationwide House Energy Rating Scheme (NatHERS) intends to reduce energy consumption by good design and construction [15]. Design includes layout of the house, construction of roof, wall, window, floor, orientation of window and shading for sun's path and local breeze etc.

Appliances consume 33\% of home energy [16] and energy rating gives a comparative assessment on appliances energy efficiency. By using energy efficient appliances and by properly utilizing appliances in daily activities, it is possible to reduce emission up to $50 \%$ [17]. In comparison with traditional cooling systems, evaporative cooling is more economical, energy efficient, best for dry hot environment and low $\mathrm{CO}_{2}$ emission $[18,19]$. Overall an energy efficient house consumes $20 \%$ less energy than a typical house [20]. Also by installing alternative energy sources such as RE sources, GHG emission can be further reduced.

\subsection{Renewable energy}

Australia is the world's 9th largest energy producer [3] and has huge potential for RE due to its strategic location. Currently, most solar energy in Australia is used for residential water heating, which accounts for around $2 \%$ of

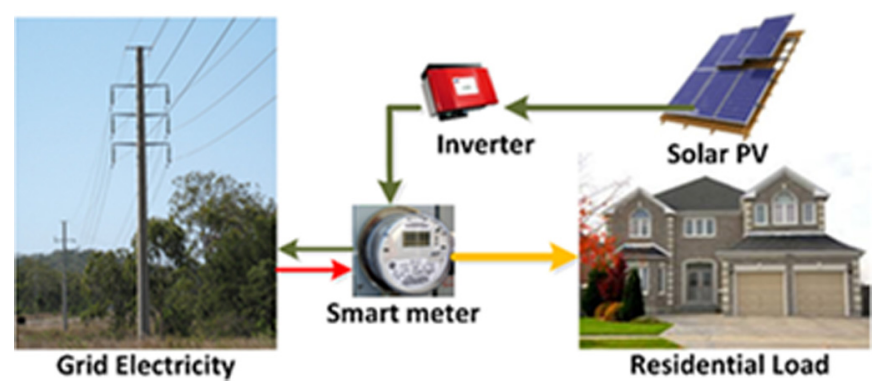

Fig. 4. A typical model in investigation.

energy consumption in residential sector [3]. The uptake of small scale solar PV has increased significantly in the past few years supported by various Australian and state/ territory government programs, such as rebates and feed-in tariffs. Geelong is an old city in Victoria and has potential for solar energy [21] as shown in Figure 3.

\subsection{Net-zero emission}

Net zero emission building is a concept that a house or building can meet its total energy demand such that yearly total emission balance from the house becomes zero. In order to achieve carbon emission to zero, it is considered to reduce energy use by improving energy efficiency and by integrating on-site RE source to reduce the grid dependency. However the consumed grid energy can be balanced by selling back the on-site generation to the grid. Victoria has approximately 2.2 million residential electricity customers [22], therefore net-zero emission building will directly help to reduce overall emission.

\section{Methodology}

In order to investigate the prospect of net-zero emission residential building in Geelong (latitude $38.22^{\circ} \mathrm{S}$, longitude $144.33^{\circ} \mathrm{E}$ ) a software model was developed as indicated in Figure 4 and yearly energy output from various capacity PV system was investigated to support the residential load. 
Table 1. Optimized system configuration.

\begin{tabular}{|c|c|c|c|c|c|}
\hline Load configurations & $\begin{array}{l}\text { Load demand } \\
\text { (kWh/year) }\end{array}$ & Required PV system & $\begin{array}{l}\text { PV supported } \\
\text { (kWh/year) }\end{array}$ & $\begin{array}{l}\text { Sell to grid } \\
(\mathrm{kWh} / \text { year })\end{array}$ & $\begin{array}{l}\text { Overall COE } \\
(\mathrm{A} \$ / \mathrm{kWh})\end{array}$ \\
\hline $\begin{array}{l}\text { I. Typical home } \\
\text { (electric load) }\end{array}$ & 4051 & $4.0 \mathrm{~kW} \mathrm{PV}$ with $2.5 \mathrm{~kW}$ inverter & 1533 & 3154 & 0.215 \\
\hline $\begin{array}{l}\text { II. Efficient home } \\
\text { (electric load) }\end{array}$ & 3234 & $3.0 \mathrm{~kW} \mathrm{PV}$ with $2.0 \mathrm{~kW}$ inverter & 1209 & 2357 & 0.215 \\
\hline $\begin{array}{l}\text { III. Typical home } \\
\text { (electric }+ \text { thermal load) }\end{array}$ & 6935 & $6.5 \mathrm{~kW} \mathrm{PV}$ with $4.0 \mathrm{~kW}$ inverter & 2558 & 5028 & 0.216 \\
\hline $\begin{array}{l}\text { IV. Efficient home } \\
\text { (electric }+ \text { thermal load) }\end{array}$ & 5548 & $5.0 \mathrm{~kW}$ PV with $3.0 \mathrm{~kW}$ inverter & 2030 & 3765 & 0.216 \\
\hline
\end{tabular}

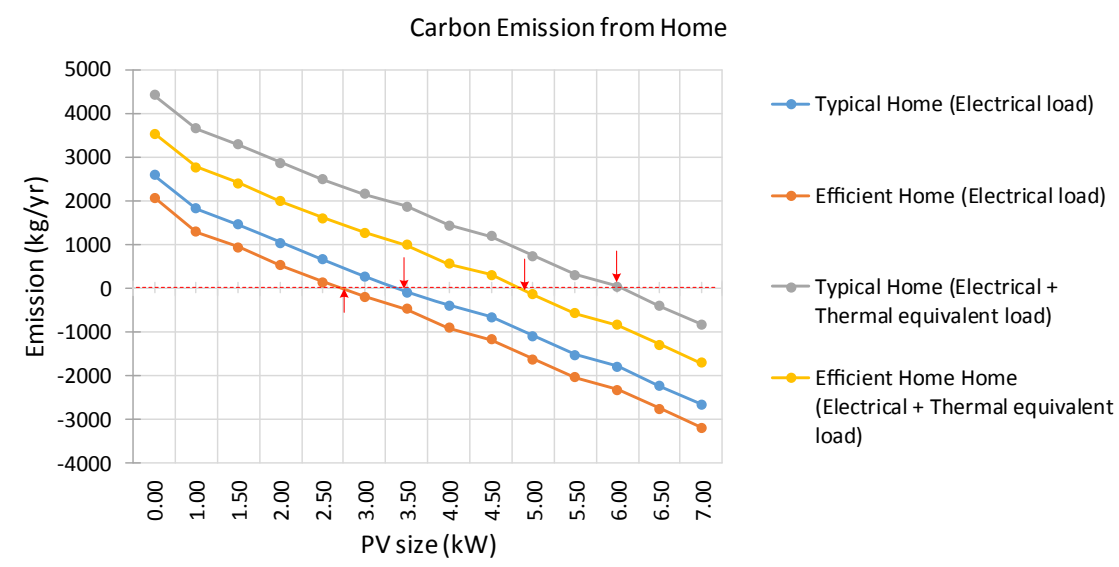

Fig. 5. Net-zero emission condition of different system configurations.

Total carbon emission considering different configuration of the PV system with present cost of each component was computed to identify the optimized system that support the load and yearly net emissions becomes zero.

\subsection{Model development}

Seasonal load, grid consumption, local generation and consumption from PV, cost of each component and emission rate are input to the model. The optimized system configuration was achieved based on total net present cost and accordingly emission from the system was compared. The emission factor considered in this model is explained in Section 2.3.

\subsection{Load consideration}

Residential load with seasonal profile was considered as shown in Figure 2. First, only electrical load was considered then thermal load was also considered but in its equivalent electrical form. Finally efficient building was considered where $20 \%$ less energy is required although the load pattern remains same.

\subsection{Cost consideration}

The cost of solar PV is decreasing over time and also decreases with increased capacity. There are different vendors operating in Australia for the residential PV system.
A $5.0 \mathrm{~kW}$ PV system including inverter and installation cost varies from $\mathrm{A} \$ 3499.00$ to $\mathrm{A} \$ 4599.0$ [23], therefore an average cost of $\mathrm{A} \$ 1100.0 / \mathrm{kW}$ was considered in the model to cover some higher price as well. Grid electricity price for residential application is distributed in peak and off-peak hours. The offpeak time is for weekends and from 11:00 PM to 7:00 AM in weekdays and all other time is considered as peak time. The rate of electricity is $\mathrm{A} \$ 0.2364 / \mathrm{kWh}$ for off-peak, $\mathrm{A} \$ 0.337$ / $\mathrm{kWh}$ for peak time which includes supply charge of $\mathrm{A} \$ 1.296$ / day and $10 \%$ goods and services tax. The sell back price is A $\$ 0.061 / \mathrm{kWh}[20]$.

\section{Results and discussions}

The simulation results showed that GHG emission or equivalent $\mathrm{CO}_{2}$ emission reduces with the integration of PV to support the load demand. Model was simulated in two load conditions, once only for electrical load and then total load that includes electrical load and thermal equivalent electrical load. Model was simulated for different PV configurations and found that under full load condition a PV system of $5.0 \mathrm{~kW}$ with $3.0 \mathrm{~kW}$ inverter generates enough energy to support load demand as well as selling enough energy to the grid that net carbon emission becomes zero.

The COE is the cost of per unit energy and expressed in $\$ / \mathrm{kWh}$. It was found that a typical house without RE installation consumed electrical load of $4051 \mathrm{kWh} /$ year 


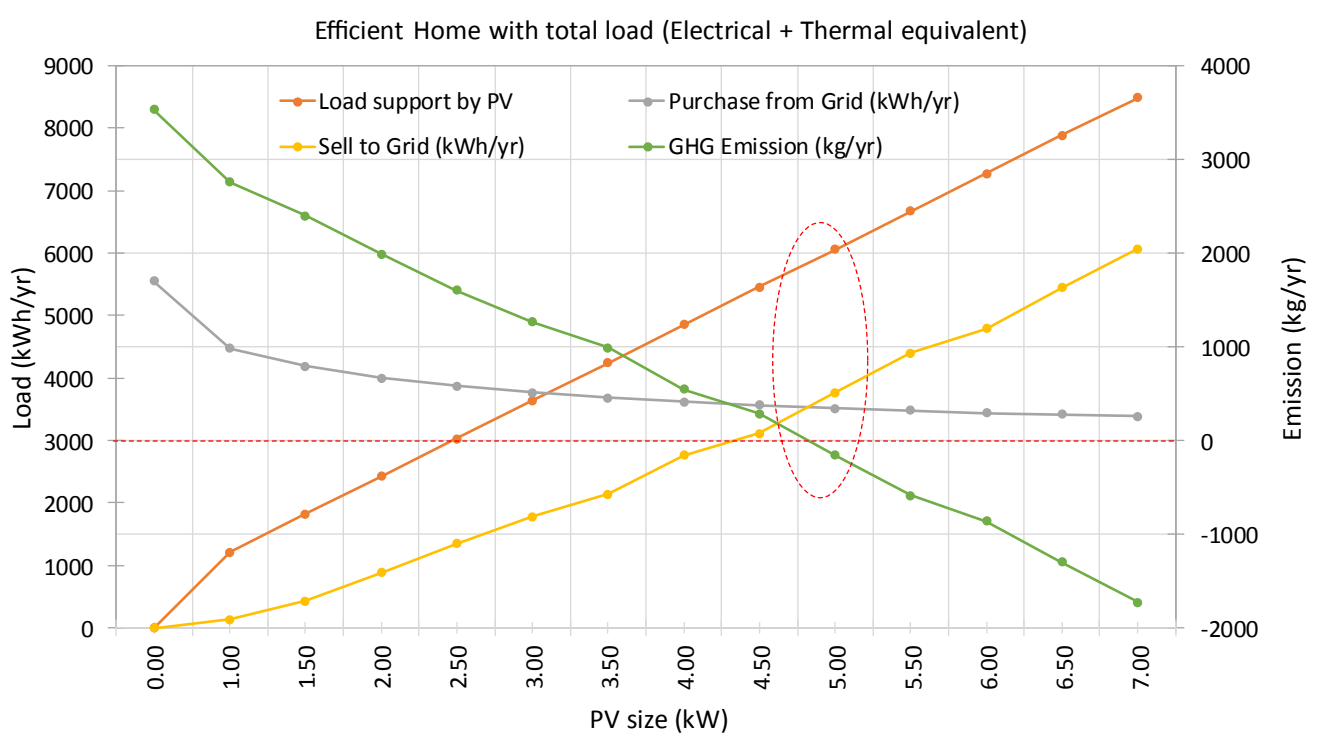

Fig. 6. Relation of load demand, PV contribution and emission in the optimized system.

Efficient Home with total load (Electrical + Thermal equivalent)

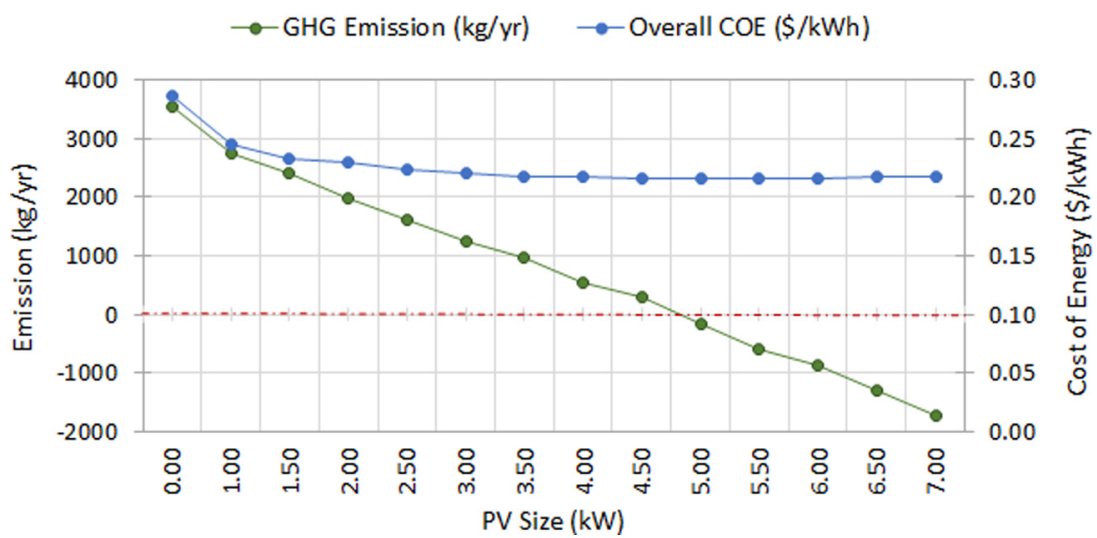

Fig. 7. Relation of COE and emission in the energy efficient residential house.

and combined electrical and thermal load of $6935 \mathrm{kWh} /$ year and the overall COE was $\mathrm{A} \$ .287 / \mathrm{kWh}$. For the energy efficient house without RE installation the electrical load was $3234 \mathrm{kWh} /$ year and combined electrical and thermal equivalent load was $5548 \mathrm{kWh} /$ year where COE was found same A $\$ 0.287 / \mathrm{kWh}$. Table 1 shows the summary of the simulation result for RE installed condition and the optimized system configurations for typical house load and energy efficient house load in Geelong Victoria. It was found that $5.0 \mathrm{~kW} \mathrm{PV} \mathrm{with}$ $3.0 \mathrm{~kW}$ inverter supports the total electrical and thermal load with overall COE of $\$ 0.216 / \mathrm{kWh}$.

Figure 5 shows the yearly total emission from the four different configurations of the system that includes solar PV to support the load. It can be seen from Figure 5 that the amount of carbon emission reduces as the installed capacity of PV increases. A typical house emits $2581 \mathrm{~kg}$ of $\mathrm{CO}_{2}$ in a year to support electrical load and $4417 \mathrm{~kg}$ of $\mathrm{CO}_{2}$ to support electrical and thermal load demand. An energy efficient house emits $2060 \mathrm{~kg}$ of $\mathrm{CO}_{2}$ to support electrical load and $3533 \mathrm{~kg}$ of $\mathrm{CO}_{2}$ to support electrical and thermal load demand. After installing PV on site a part of the load demand was met by PV and due to unmatched profile of load and PV generation, a part of the energy from PV was sold back to grid. From the simulation it was found that $5.0 \mathrm{~kW}$ PV system is sufficient to support the total electrical and thermal load demand that overall $\mathrm{CO}_{2}$ emission becomes zero and ensures net-zero emission condition of the three-bedroom house. Figure 5 also indicates the required system in different load conditions. Figure 6 illustrates the relation of an efficient house load demand with grid support, PV capacity, $\mathrm{PV}$ output and $\mathrm{CO}_{2}$ emission. It also indicates the point when the whole system becomes a net-zero emission system. COE become stable after sufficient size of PV installation, however increased size PV helped to reduce the $\mathrm{CO}_{2}$ emission further as illustrated clearly in Figure 7. 


\section{Conclusion}

This paper investigated a residential load demand in a temperate weather condition in Australia and identified the optimized system configurations to make a yearly equivalent net-zero emission from the residential building. The findings showed that the required PV system for a typical house is larger to make emission to zero, however the system size can be reduced by making energy efficient house. In this configuration the net energy production is higher than yearly net load demand due to the uneven relation of buying and selling price of electrical energy. This finding clearly indicates that one house in Geelong can save $4417 \mathrm{~kg}$ of $\mathrm{CO}_{2}$ emission each year, therefore 9 million Australian houses can save approximately $44 \mathrm{Mt}$ (million tons) of $\mathrm{CO}_{2}$ emission each year which is a great support to achieve the emission reduction target.

\section{References}

1. P. Pham, A. Ball, S. Ahmad, G. Bragatheswaran, C. McCluskey, C. Tisdell et al., Energy in Australia 2015 (Office of the Chief Economist, Department of Industry, Innovation and Science, Australian Government, 2016)

2. C.O. Australia, The Australian Government's Action on Climate Change (Fact Sheet, Department of the Environment and Energy, Australian Government, 2016)

3. K. Penney, A. Schultz, A. Ball, N. Hitchins, C.S.A.K. Martin, Energy in Australia 2012 (Report, Bureau of Resources and Energy Economics, Department of Resources, Energy and Tourism, Australian Government, 2012)

4. T. Willcock, N. Che, C. McCluskey, Energy in A ustralia 2013 (Bureau of Resources and Energy Economics, Department of Resources, Energy and Tourism, Australian Government, 2013)

5. C.O. Australia, 3236.0 - Household and Family Projections, Australia, 2011 to 2036 (Australian Bureau of Statistics, 2015), Available from: http://www.abs.gov.au/ausstats/ abs@.nsf/Latestproducts/3236.0Main\%20Features42011\% 20to\%202036 [accessed 23.09.2016]

6. R. de Dear, G. Schiller Brager, The adaptive model of thermal comfort and energy conservation in the built environment, Int. J. Biometeorol. 45, 100 (2001)

7. L. Pérez-Lombard, J. Ortiz, C. Pout, A review on buildings energy consumption information, Energy Build. 40, 394 (2008)

8. K. Voss, E. Musall, Net zero energy solar buildings, in Solar Heating \& Cooling Programme, SHC Task 40, International Energy Agency (IEA) (2012), Available from: http://task40. iea-shc.org [accessed 23.10.2015]

9. F.P. Sioshansi, Distributed Generation and its Implications for the Utility Industry (Elsevier Science, 2014)

10. AccuWeather, Weather for Geelong (2014), Available from: http://www.accuweather.com/en/au/geelong/15892/ month $/ 15892$ ?monyr=1/01/2013 [accessed 15.04.2014]
11. EnergyMadeEasy, Understand and Compare your Home Electricity Usage (Australian Government, 2016), Available from: https://www.energymadeeasy.gov.au/benchmark [accessed 07.01.2017]

12. Deloitte Australia, Advanced Metering Infrastructure Customer Impacts Study, Final Report: Volume 1 (Department of Primary Industries, 2011), Available from: http://www. smartmeters.vic.gov.au/__data/assets/pdf_file/0008/1175 858/CIS-Final-report-18-Oct-Volume-1.pdf [accessed 07.01.2017, 18.10.2011]

13. M.T. Arif, A.M. Oo, A. Ali, G. Shafiullah, Significance of storage on solar photovoltaic system: a residential load case study in Australia, Smart Grid Renew. Energy 4, 167 (2013)

14. Leonardo ENERGY, Net Zero Energy Homes (2011), Available from: http://www.leonardo-energy.org/resour ces/587/net-zero-energy-homes-581b3ca484413 [accessed 17.11.2015]

15. M. Ambrose, M. Syme, House Energy Efficiency Inspections Project (Energy Flagship, Final Report, CSIRO, Australia, 2015), Available from: http://nathers.gov.au/sites/prod. nathers/files/publications/House\%20Energy\%20Efficiency \%20Inspect\%20Proj.pdf [accessed 25.11.2016]

16. C. Riedy, G. Milne, Your Home, Australia's Guide to Environmentally Sustainable Homes (Australian Government, 2013), Available from: http://yourhome.gov.au/ener gy/appliances [accessed 25.11.2016]

17. D.J. Wright, D.P. Osman, P. Ashworth, The CSIRO Home Energy Saving Handbook - How to Save Energy, Save Money and Reduce Your Carbon Footprint (2009), p. 240

18. Air \& Water, Evaporative Cooling vs. Air Conditioning: A True Comparison (2017), Available from: http://www.air-nwater.com/evaporative-cooler-ac-comparison.htm [accessed 07.01.2017]

19. Cool Breeze, Cool Breeze Air Conditioning, Evaporative vs Reverse Cycle Air conditioning (2016), Available from: https://www.coolbreeze.com.au/reverse-cycle-air-condition ing/ [accessed 07.01.2017]

20. AGL, AGL Electricity - Energy Price, Collected Price Data (2016), Available from: www.agl.com.au/residential/energyplans/ [accessed 21.11.2016]

21. J.M. Kusterer, NASA Surface Meteorology and Solar Energy - Location (Atmospheric Science Data Center, 2013), Available from: https://eosweb.larc.nasa.gov/cgi-bin/sse/ grid.cgi [accessed 08.09.2013]

22. Smartmeters, About Smart Meters, Advanced Metering Infrastructure Customer Impacts Study - Volume 1, The Victorian Electricity Market Region (Victorian State Government, 2016), Available from: http://www.smart meters.vic.gov.au/about-smart-meters/reports-and-consultations/advanced-metering-infrastructure-customer-impacts -study-volume-1/2-background [accessed 07.01.2017]

23. Clean Technology Services, Solar PV system price, Available from: http://www.cleantechnologyservices.com.au/special/ [accessed 29.12.2016]

Cite this article as: Mohammad T. Arif, Amanullah M. Than Oo, Net-zero emission residential building in temperate weather condition, Renew. Energy Environ. Sustain. 2, 30 (2017) 